\title{
MODEL PILIHAN PENUMPANG ANGKUTAN KOTA DAN KERETA REL LISTRIK DI JAKARTA
}

\author{
Mezky Matthew Yandito \\ Kelompok Ilmu Transportasi \\ Departemen Teknik Sipil \\ Universitas Indonesia \\ Depok 16424 \\ mezkymy@gmail.com
}

\author{
Alvinsyah \\ Kelompok Ilmu Transportasi \\ Departemen Teknik Sipil \\ Universitas Indonesia \\ Depok 16424 \\ alvinsyah2004@gmail.com
}

\begin{abstract}
With the operation of the Electric Rail Train in the Jakarta Kota-Tanjung Priok route at the end of 2015, it is estimated that there is a potential for the transfer of passengers from other modes to the Electric Rail Train. The purpose of this study is to estimate the factors that influence passenger preferences in traveling on the Jakarta Kota-Tanjung Priok route and form a demand analysis tool in the form of a modal choice model. The analysis was carried out using the binomial logit model approach which was developed based on the stated preference survey results on public transportation passengers that traveled on the similar route as the route where the Electric Rail Train operates. The factors included in the stated preference survey were obtained through literature studies and interviews, and through a pilot survey 3 factors were chosen which most influenced the mode choice. Based on the results of the correlation test, it was found that the variable that most influences the mode choice is the tariff.
\end{abstract}

Keywords: passenger preferences, choice model, stated preference, tariff

\begin{abstract}
Abstrak
Dengan beroperasinya Kereta Rel Listrik rute Jakarta Kota-Tanjung Priok pada akhir tahun 2015, diperkirakan terdapat potensi perpindahan penumpang dari moda lainnya ke Kereta Rel Listrik. Tujuan penelitian ini adalah untuk memperkirakan faktor-faktor yang memengaruhi preferensi penumpang dalam melakukan perjalanan di rute Jakarta Kota-Tanjung Priok dan membentuk perangkat analisis permintaan berbentuk model pemilihan moda. Analisis dilakukan dengan menggunakan pendekatan model logit binomial yang dikembangkan berdasarkan hasil survei stated preference terhadap penumpang angkot yang melalui rute yang sama dengan rute Kereta Rel Listrik. Faktor-faktor yang dimasukkan dalam survei stated preference diperoleh melalui studi literatur dan wawancara, dan melalui survei pilot dipilih 3 faktor yang dinilai paling memengaruhi pilihan moda. Berdasarkan hasil uji korelasi ditemukan bahwa variabel yang paling berpengaruh terhadap pilihan moda adalah tarif.
\end{abstract}

Kata-kata kunci: preferensi penumpang, model pemilihan, stated preference, tarif

\section{PENDAHULUAN}

Kereta Rel Listrik (KRL) merupakan suatu moda transportasi massal yang beroperasi di daerah Jabodetabek dengan nama Commuter Line. Berdasarkan data PT KAI Commuter Line Jabodetabek (KCJ), penumpang KRL pada tahun 2015 mencapai sekitar 850.000 orang per hari, sedangkan untuk tahun 2019 PT KCJ memiliki target jumlah penumpang sebanyak 1,2 juta orang per hari. Meskipun demikian, jumlah penumpang KRL Jabodetabek masih relatif kecil jika dibandingkan dengan jumlah pengguna moda lainnya, khususnya kendaraan pribadi. Survei Jabodetabek Urban Transportation Policy 
Integration Project (JUTPI) menyatakan bahwa penggunaan moda angkutan umum di Kawasan Jabodetabek menurun seiring meningkatnya penggunaan kendaraan pribadi dari tahun 2002 ke tahun 2010 (The Coordinating Ministry of Economic Affairs; Japan International Coorporation Agency, 2012). Sebagai moda yang lebih efisien dalam penggunaan bahan bakar dan lebih ramah lingkungan dibandingkan sepeda motor, mobil pribadi, dan bus (Bradley, 2007), banyak upaya yang perlu dilakukan untuk meningkatkan pelayanan KRL Jabodetabek agar lebih banyak pengguna moda transportasi lainnya beralih ke KRL.

Terhitung mulai tanggal 21 Desember 2015, rute KRL Jakarta Kota-Tanjung Priok resmi diaktifkan kembali. Masih terdapat beberapa moda transportasi umum lain yang beroperasi pada rute ini menyebabkan faktor muat penumpang moda KRL pada rute tersebut masih kecil, dengan jumlah penumpang per gerbongnya hanya mencapai sekitar 30 penumpang untuk tiap perjalanan, padahal kapasitas maksimal per gerbong untuk kereta yang digunakan pada rute Jakarta Kota-Tanjung Priok adalah 160 orang. Dengan demikian, terdapat potensi perpindahan penumpang dari moda-moda lainnya ke KRL, jika KRL lebih menarik daripada moda-moda lain tersebut.

Penelitian ini dimaksudkan untuk memperkirakan faktor-faktor yang dapat memengaruhi preferensi penumpang dalam melakukan perjalanan di rute Jakarta Kota-Tanjung Priok. Faktor-faktor tersebut selanjutnya digunakan untuk membentuk suatu model yang dapat menunjukkan preferensi penumpang dalam memilih suatu moda.

Secara garis besar, tahapan-tahapan yang dilakukan dalam penelitian ini dibagi menjadi beberapa segmen, yaitu tahap pendahuluan, survei awal, survei pilot, survei utama, pengolahan dan interpretasi data, pengembangan model (yang terdiri atas uji korelasi, pembentukan kelompok sampel, pembentukan fungsi utilitas, dan kalibrasi), validasi split sample, serta kesimpulan dan saran. Alur tahapan tersebut dapat dilihat pada Gambar 1.

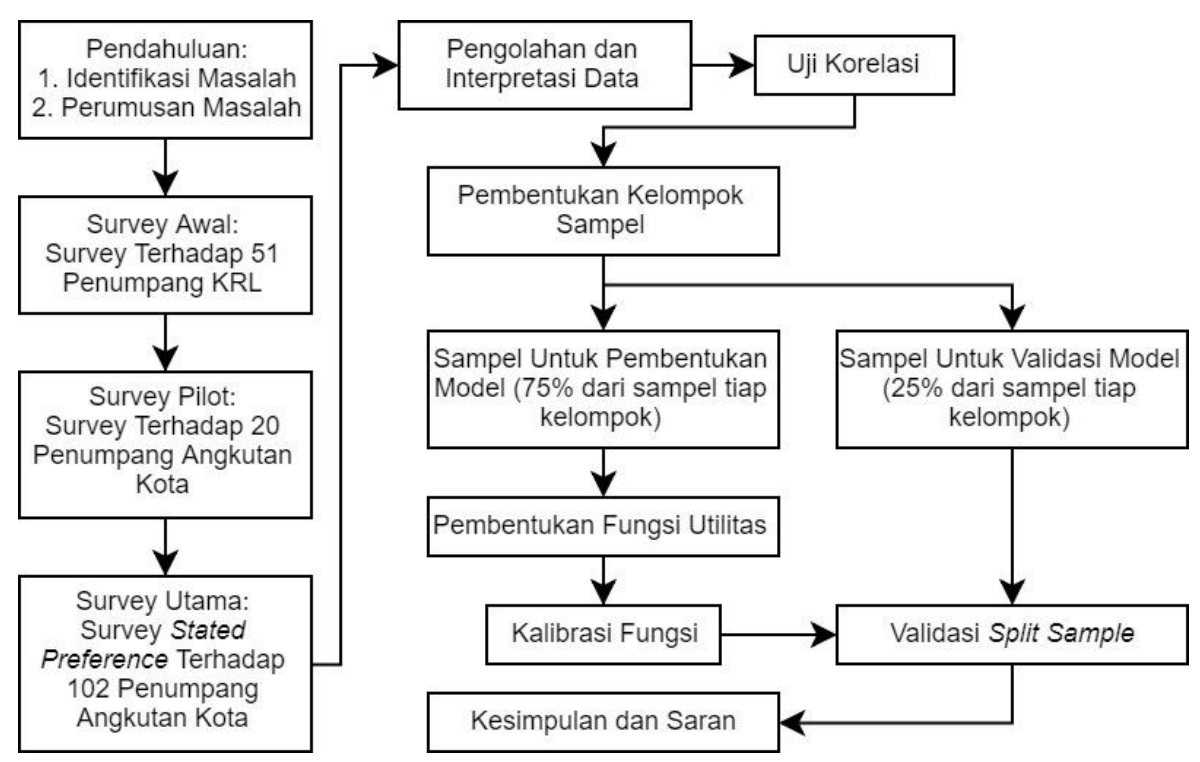

Gambar 1 Diagram Alur Penelitian 
Dalam pemilihan atau persebaran moda transportasi, pengguna jasa dianggap menggunakan moda yang memiliki nilai utilitas (U) yang lebih besar. Probabilitas pemilihan moda dapat dilakukan dengan membandingkan nilai U masing-masing moda menggunakan model logit, yang ditunjukkan dalam rumus (Ortuzar dan Willumsen, 2011):

$$
P_{i q}=\frac{e^{-U_{i q}}}{e^{-U_{i q}+e^{-U_{j q}}}}
$$

dengan:

$P_{i q}=$ proporsi atau probabilitas perjalanan individu $q$ dengan menggunakan moda $i$, $e^{-U i q}=$ eksponensial dari nilai utilitas individu $q$ terhadap moda $i$.

Utilitas adalah konsep pengukuran preferensi terhadap suatu barang ataupun jasa (Blokhin, 2016). Utilitas untuk suatu individu oleh suatu pilihan moda atau alternatif dapat dikatakan sebagai mengukur preferensi yang dimiliki individu terhadap pilihan atau kombinasi pilihan tersebut (Oppenheim, 1995). Fungsi utilitas dinyatakan oleh Oppenheim (1995) dalam persamaan:

$$
U_{j q}=V_{j q}+\varepsilon_{j q}
$$

dengan:

$V_{j q}=$ fungsi deterministik utilitas moda $j$ bagi individu $q$,

$\varepsilon_{\mathrm{jq}}=$ kesalahan acak atau komponen stokastik.

Untuk kondisi ketika kemungkinan yang dapat terjadi hanya ada 2, model dinamakan sebagai binary logit model atau model logit biner. Pada model ini, opsi dinyatakan dalam angka biner, dengan 0 merepresentasikan opsi pertama dan 1 merepresentasikan opsi kedua. Pembentukan model logit biner dilakukan setelah fungsi utilitas diperoleh. Model logit biner digunakan untuk memperoleh nilai probabilitas terjadinya suatu kejadian terhadap kejadian lainnya. Pada studi ini kejadian pertama adalah responden memilih untuk menggunakan moda angkot dan kejadian kedua responden memilih untuk menggunakan moda KRL. Bila dirumuskan, probabilitas seseorang menggunakan moda KRL menjadi:

$$
P_{K R L}=\frac{e^{(U)}}{1+e^{(U)}}=\frac{1}{1+e^{-(U)}}
$$

Sedangkan probabilitas seseorang tetap menggunakan angkot adalah 1-P $\mathrm{P}_{\mathrm{KRL}}$.

Sebelum dibentuk menjadi model, terlebih dahulu seluruh sampel diuji korelasi antarvariabelnya. Kemudian, untuk memperoleh nilai korelasi yang lebih baik, dilakukan pengelompokan sampel sesuai dengan kesamaan pada salah satu variabelnya. Untuk memperoleh kelompok data yang lebih homogen, sampel dikelompokkan menjadi sampel yang menggunakan angkot dari ujung ke ujung trayek dan sampel yang turun dan naik 
antara Stasiun Jakarta Kota dan Terminal Tanjung Priok. Alur pembagian kelompok sampel dapat dilihat pada Gambar 2. Kemudian tiap-tiap kelompok diuji korelasi antarvariabelnya untuk mengetahui nilai koefisien korelasi terhadap kelompok induknya.

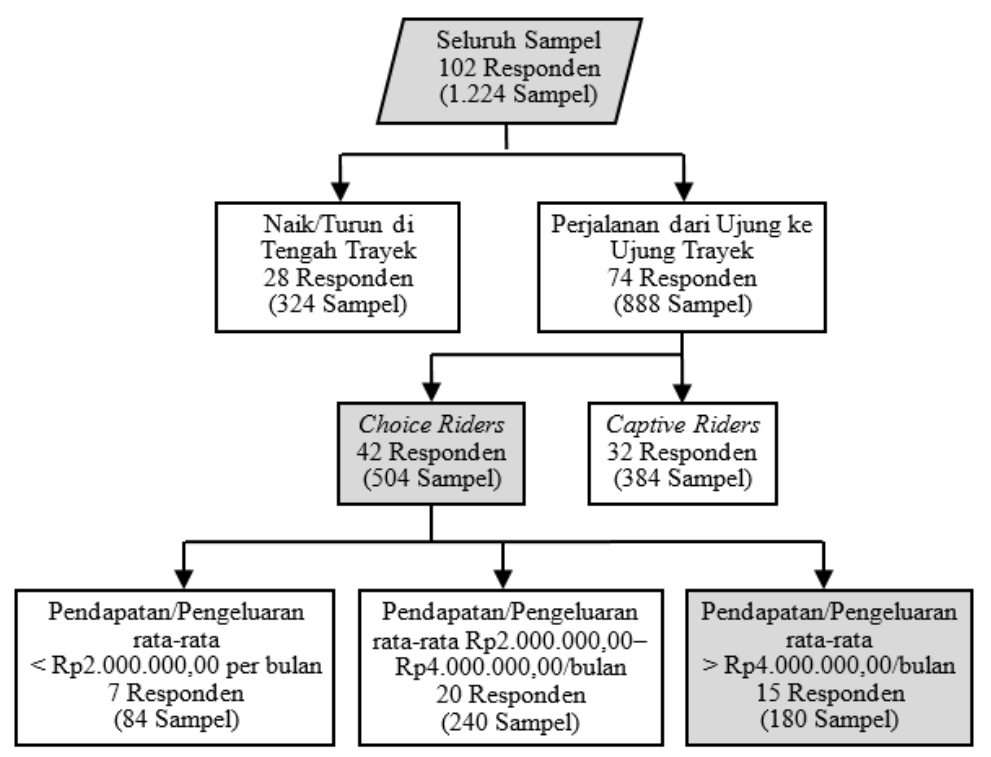

Gambar 2 Kombinasi Sampel yang Diujikan

Model yang terbentuk kemudian divalidasi dengan metode split sample validation, dengan cara nilai probabilitas pada model dibandingkan dengan nilai probabilitas pembanding, yang diperoleh melalui penghitungan rasio pemilihan moda KRL terhadap angkot dari sampel yang tidak dimasukkan ke dalam pembentukan model, yang pada grafik ditunjukkan sebagai nilai riil. Root Mean Square Error (RMSE) adalah salah satu tolok ukur yang dapat digunakan untuk melihat perbedaan antara nilai yang diprediksi terhadap nilai observasi, yang diperoleh dengan mencari akar selisih nilai deviasi standar antara probabilitas model dengan rasio riil, seperti yang dapat dilihat pada persamaan (Armstrong dan Collopy, 1992):

$$
R M S E=\sqrt{\left|\sigma_{\text {model }}-\sigma_{\text {riil }}\right|}
$$

dengan $\sigma$ merupakan nilai deviasi standar data yang dimiliki.

\section{HASIL PENELITIAN}

Variabel yang digunakan pada penelitian ini diperoleh melalui studi literatur dan survei pendahuluan, yang kemudian diuji lebih lanjut pada survei pilot. Terdapat 5 variabel yang dianggap memengaruhi pilihan moda, yaitu Frekuensi, Waktu Tunggu, Reliabilitas, Akses, dan Jangka Waktu Operasional (Transportation Research Board, 2013). Faktor yang juga dapat memengaruhi preferensi pengguna adalah karakteristik pengguna dan karakteristik perjalanan. Karakteristik pengguna terdiri atas ketersediaan kendaraan pribadi, struktur rumah tangga (misalnya jumlah anggota keluarga dan usia anggota 
keluarga), kepadatan tempat tinggal, dan pendapatan. Sedangkan karakteristik perjalanan terkait dengan tujuan, jarak, dan jumlah pengguna yang melakukan perjalanan, baik sendiri atau dengan yang lain (Mathew dan Rao, 2006). Setelah survei pendahuluan dan survei pilot dilakukan, variabel Waktu Perjalanan, Tarif, dan Frekuensi diperoleh sebagai 3 variabel yang menurut responden paling berpengaruh terhadap pilihan moda. Dalam survei utama, variabel yang diuji korelasinya adalah ketiga variabel tersebut ditambah dengan beberapa karakteristik pengguna dan perjalanan. Keseluruhan variabel yang diuji adalah Waktu Perjalanan, Frekuensi, Tarif KRL (dalam ribuan rupiah), Moda yang Dipilih (dummy), Jenis Kelamin, Usia, Pendidikan Terakhir, Pendapatan/Pengeluaran Rata-Rata Per Bulan, Tujuan Perjalanan, Total Biaya Perjalanan, Kepemilikan Kendaraan Pribadi yang Dapat Digunakan, dan Choice/Captive Rider.

Dari seluruh variabel tersebut, diperoleh korelasi yang signifikan dengan tingkat keandalan 0,05 atau 5\% antara variabel moda yang dipilih dengan hampir seluruh variabel lainnya, kecuali waktu perjalanan dan pendidikan terakhir. Nilai koefisien korelasi lebih besar daripada 0,1 hanya diperoleh untuk hubungan antara pilihan moda dengan tarif KRL, kepemilikan kendaraan pribadi yang dapat digunakan, dan choice atau captive rider; sedangkan hanya variabel tarif KRL yang memiliki nilai koefisien korelasi lebih besar daripada 0,2. Angka koefisien yang lebih kecil daripada 0,5 menunjukkan korelasi yang tidak erat (Santoso, 2014), sehingga dapat disimpulkan bahwa seluruh variabel tidak ada yang memiliki ikatan erat, meskipun model tetap dapat dibentuk antara variabel-variabel yang memiliki korelasi signifikan.

Melalui uji korelasi per kombinasi kelompok data, diperoleh 3 kombinasi yang menunjukkan peningkatan nilai koefisien korelasi terhadap nilai yang diperoleh pada uji korelasi kelompok induknya, yaitu kombinasi responden dengan perjalanan dari ujung ke ujung trayek yang memiliki ukuran samel 888 dengan koefisien korelasi antara tarif KRL dengan pilihan moda sebesar -0,246 (Grup A), choice riders yang memiliki ukuran sampel 504 dengan koefisien korelasi antara tarif KRL dengan pilihan moda sebesar -0,278 (Grup B), dan kombinasi choice riders yang berpendapatan atau berpengeluaran rata-rata di atas Rp4.000.000,00 per bulan dengan koefisien korelasi antara tarif KRL dengan pilihan moda sebesar - 0,436 (Grup C).

\section{Fungsi Utilitas dan Validasi}

Berdasarkan hasil uji korelasi, dibentuk 3 model fungsi utilitas untuk tiap grup yang dipilih. Dalam tiap-tiap kombinasi, diambil sekitar 25\% dari sampel atau maksimal sebanyak 10 responden (120 sampel) secara acak yang tidak diikutkan dalam pembentukan model yang digunakan untuk menguji model yang dibentuk dari sampel lainnya. Kalibrasi kemudian dilakukan pada tahap pembentukan model dengan tujuan untuk memastikan bahwa model tidak melanggar ekspektasi teoritis dan konsisten secara internal, atau dalam arti tidak melanggar asumsi yang digunakan untuk membentuk model itu sendiri (Meyer dan Miller, 1984). Nilai-nilai kalibrasi regresi yang juga diperoleh ketika melakukan pembentukan model, nilai Chi-square melalui uji Omnibus serta Hosmer dan Lemeshow 
(Hosmer dan Lemeshow, 2000) digunakan untuk menilai model berdasarkan signifikansinya terhadap null hypothesis, sedangkan Nagelkerke $R$ Square (Nagelkerke, 1991) dan Overall Percentage digunakan untuk menilai model berdasarkan kemampuannya merepresentasikan data yang digunakan untuk membentuk model tersebut. Nilai -2 Loglikelihood digunakan pada proses iterasi model, sedangkan nilai Wald digunakan untuk menghitung signifikansi berdasarkan derajat kebebasannya $(d f)$. Dalam fungsi yang dibentuk, biaya dinyatakan dalam satuan ribuan rupiah dan frekuensi dinyatakan dalam menit per satu perjalanan.

Pada Grup A, terdapat koefisien regresi variabel Tarif KRL (variabel $x$ ) sebesar -0,486 dan konstanta sebesar 2,860. Berdasarkan model, meningkatnya tarif KRL mengurangi kecenderungan responden untuk menggunakan KRL seiring dengan menurunnya nilai utilitas. Nilai Chi-square dengan derajat kebebasan $(d f)$ yang diperoleh dari uji Hosmer dan Lemeshow menunjukkan nilai alpha di rentang 0,1-0,05, dengan nilai Sig. Lebih besar daripada 0,05. Sedangkan melalui uji Omnibus diperoleh nilai Sig. Lebih kecil daripada 0,05. Dengan demikian model dapat diterima. Model dapat menjelaskan data yang digunakan, untuk membentuk model tersebut dengan akurasi 63,10\%, dan model dapat menjelaskan $8,40 \%$ variansi pada moda pilihan. Variabel, hasil-hasil pengujian model, dan atribut lainnya pada model yang dibentuk dapat dilihat pada Tabel 1.

Tabel 1 Fungsi Utilitas Grup A

\begin{tabular}{|c|c|c|c|c|c|}
\hline Variabel & Koefisien & S.E. & Wald & df & Sig. \\
\hline Tarif KRL (dalam ribu rupiah) & $-0,486$ & 0,072 & 45,379 & 1 & 0 \\
\hline Konstanta & 2,860 & 0,347 & 68,103 & 1 & 0 \\
\hline Omnibus test of model coefficients & & chi-square $=$ & 48,294 & 1 & 0 \\
\hline Hosmer dan Lemeshow test & & chi-square $=$ & 4,880 & 2 & 0,087 \\
\hline Overall Percentage & \multicolumn{5}{|c|}{$63,10 \%$} \\
\hline -2 Loglikelihood & \multicolumn{5}{|c|}{943,937} \\
\hline Nagelkerke R Square & \multicolumn{5}{|c|}{$8,40 \%$} \\
\hline Fungsi Utilitas & \multicolumn{5}{|c|}{$\mathrm{U}=-0,486 \mathrm{x}+2,860$} \\
\hline
\end{tabular}

Pada Grup B, terdapat dua variabel yang signifikan dan tidak memiliki korelasi kuat dengan variabel lainnya selain pilihan moda, yaitu frekuensi perjalanan dan tarif KRL. Oleh karena itu, dibentuk 2 model terpisah, dengan 1 model hanya menggunakan variabel tarif (Tabel 2) dan model lainnya menggunakan variabel tarif dan frekuensi (Tabel 3). Pada model 2 variabel, variabel frekuensi dinyatakan sebagai $y$. Dari kedua fungsi yang dibentuk, terdapat perbedaan konstanta yang signifikan, yaitu 2,77 dan 3,879. Koefisien tarif KRL sendiri tidak berubah banyak di kedua fungsi. Persentase keseluruhan, -2 Loglikelihood dan nilai $\mathrm{R}^{2}$ juga tidak banyak berubah.

Hal yang perlu diperhatikan adalah bahwa pada fungsi utilitas dengan 2 variabel, variabel frekuensi $(y)$ memiliki angka Sig. yang tinggi (lebih besar daripada 0,05), sehingga model dapat dikatakan kurang baik untuk digunakan, atau dapat dikatakan bahwa frekuensi tidak berpengaruh dalam fungsi utilitas. Pada model dengan 1 variabel, model dapat menjelaskan data yang digunakan untuk membentuk model tersebut dengan akurasi $61,70 \%$, dan model dapat menjelaskan 10,70\% variansi pada moda pilihan. Atribut lainnya pada model-model yang dibentuk dapat dilihat pada Tabel 2 dan Tabel 3. 
Tabel 2 Fungsi Utilitas Grup B dengan Satu Variabel

\begin{tabular}{|c|c|c|c|c|c|}
\hline Variabel & Koefisien & S.E. & Wald & df & Sig. \\
\hline Tarif KRL (dalam ribuan) & $-0,542$ & 0,099 & 29,699 & 1 & 0 \\
\hline Konstanta & 2,77 & 0,47 & 34,753 & 1 & 0 \\
\hline Omnibus test of model coefficients & & chi-square $=$ & 31,975 & 1 & 0 \\
\hline Hosmer dan Lemeshow test & & chi-square $=$ & 1,853 & 2 & 0,396 \\
\hline Overall Percentage & & & $61,70 \%$ & & \\
\hline-2 Loglikelihood & & & 491,568 & & \\
\hline Nagelkerke R Square & & & $10,70 \%$ & & \\
\hline Fungsi Utilitas & \multicolumn{5}{|c|}{$\mathrm{U}=-0,542 \mathrm{x}+2,77$} \\
\hline
\end{tabular}

Tabel 3 Fungsi Utilitas Grup B dengan Dua Variabel

\begin{tabular}{lccccc}
\hline Variabel & Koefisien & S.E. & Wald & df & Sig. \\
\hline Tarif KRL (dalam ribuan) & $-0,547$ & 0,1 & 29,898 & 1 & 0 \\
Frekuensi Perjalanan (menit/perjalanan) & $-0,072$ & 0,04 & 3,192 & 1 & $\mathbf{0 , 0 7 4}$ \\
Konstanta & 3,879 & 0,79 & 24,091 & 1 & 0 \\
Omnibus test of model coefficients & & chi-square $=$ & 35,213 & 2 & 0 \\
Hosmer dan Lemeshow test & chi-square $=$ & 6,281 & 6 & 0,392 \\
Overall Percentage & & $61,70 \%$ & & \\
-2 Loglikelihood & & 488,33 & \\
Nagelkerke R Square & \multicolumn{3}{c}{$11,80 \%$} \\
Fungsi Utilitas & $\mathrm{U}=-0,547 \mathrm{x}-0,072 \mathrm{y}+3,879$ \\
\hline
\end{tabular}

Pada Grup C, diambil 4 responden yang tidak dimasukkan dalam pembentukan fungsi utilitas, sehingga hanya 11 responden yang digunakan untuk membentuk model. Perlu diperhatikan bahwa hal ini kurang sesuai dengan rekomendasi minimal yang dinyatakan oleh Rose dan Bliemer (2009), yaitu minimal responden adalah 30. Karena batasan minimal tersebut hanya berupa rekomendasi, pada studi ini model tetap dibentuk dengan 11 responden. Model dapat menjelaskan data yang digunakan dengan akurasi 71,20\% dan dapat menjelaskan $22,10 \%$ variansi pada moda pilihan. Nilai tersebut merupakan nilai tertinggi jika dibandingkan dengan nilai untuk model-model lainnya.

Tabel 4 Fungsi Utilitas Grup C

\begin{tabular}{|c|c|c|c|c|c|}
\hline Variabel & Koefisien & S.E. & Wald & $\mathrm{df}$ & Sig. \\
\hline Tarif KRL (dalam ribuan) & $-0,916$ & 0,219 & 17,437 & 1 & 0 \\
\hline Konstanta & 5,377 & 1,116 & 23,221 & 1 & 0 \\
\hline Omnibus test of model coefficients & & square $=$ & 21,672 & 1 & 0 \\
\hline Hosmer dan Lemeshow test & & square $=$ & 5,096 & 2 & 0,078 \\
\hline Overall Percentage & \multicolumn{5}{|c|}{$71,20 \%$} \\
\hline -2 Loglikelihood & \multicolumn{5}{|c|}{131,02} \\
\hline Nagelkerke R Square & \multicolumn{5}{|c|}{$22,10 \%$} \\
\hline Fungsi Utilitas & \multicolumn{5}{|c|}{$\mathrm{U}=-0,916 \mathrm{x}+5,377$} \\
\hline
\end{tabular}

\section{Validasi Model Logit Biner}

Dengan menggunakan ketiga persamaan yang ada, dibentuk grafik yang membandingkan nilai probabilitas penggunaan moda KRL berdasarkan model yang dibentuk (Model) dengan nilai probabilitas yang diperoleh dari sampel yang digunakan untuk pengujian (Real). Pada grafik model logit yang dibentuk, sumbu $\mathrm{x}$ adalah nilai utilitas (U) yang diperoleh dengan memasukkan kombinasi nilai-nilai variabel ke dalam fungsi utilitas yang telah dibentuk, sedangkan sumbu y adalah probabilitas penggunaan 
moda KRL dibandingkan moda angkot. Grafik untuk ketiga fungsi dapat dilihat pada Gambar 3.

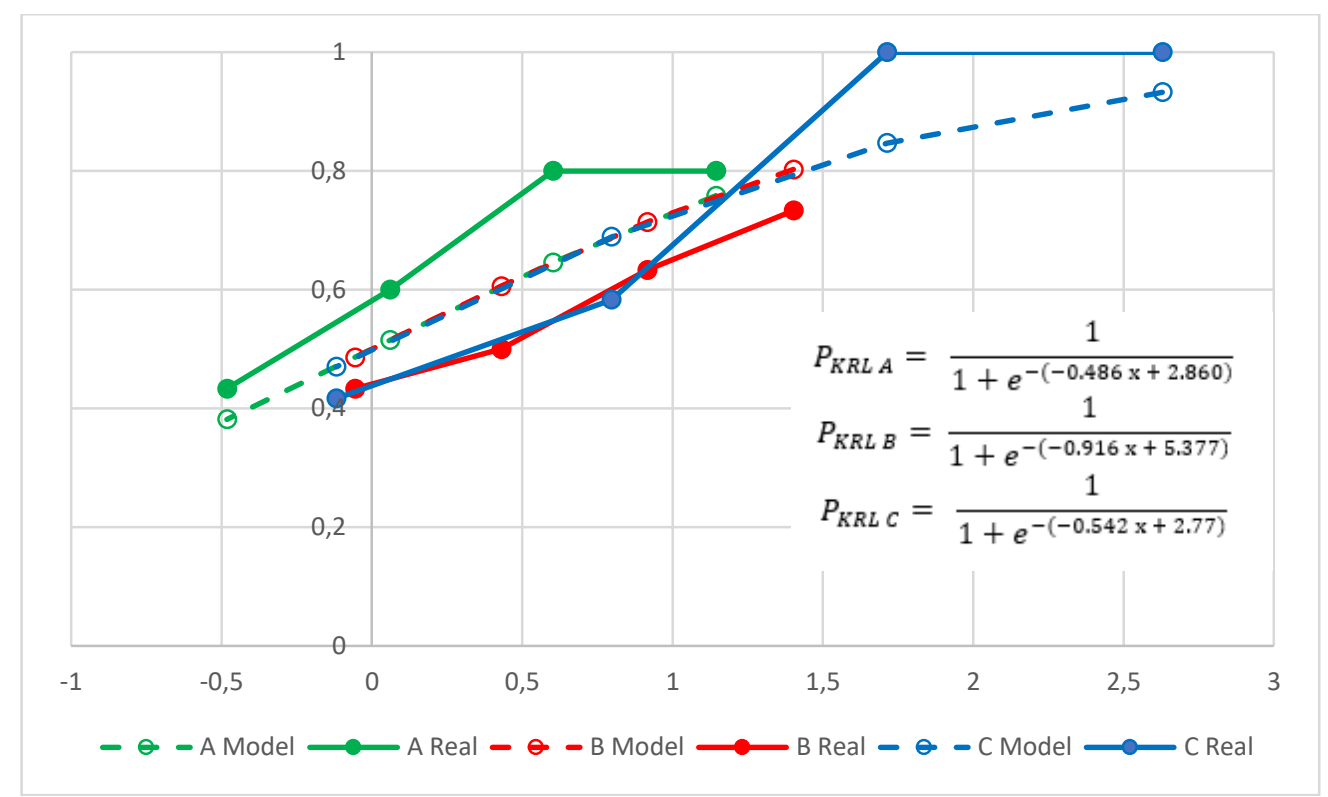

Gambar 3 Perbandingan Nilai Probabilitas Model terhadap Real

Persentase eror adalah nilai yang diperoleh dengan membandingkan antara selisih nilai probabilitas Model dan nilai Real dengan nilai probabilitas model sebagai nilai pembanding. Besar persentase eror pada tiap grup dapat dilihat pada Tabel 5.

Tabel 5 Perbandingan Nilai Probabilitas Model terhadap Real

\begin{tabular}{crrr}
\hline \multirow{2}{*}{ Tarif KRL (dalam Ribuan Rupiah) } & \multicolumn{3}{c}{ Persentase Eror } \\
\cline { 2 - 4 } & Grup A & Grup B & Grup C \\
\hline 3 & $8,62 \%$ & $5,48 \%$ & $7,22 \%$ \\
4 & $11,33 \%$ & $23,82 \%$ & $18,03 \%$ \\
5 & $17,47 \%$ & $16,51 \%$ & $15,38 \%$ \\
6 & $10,84 \%$ & $13,50 \%$ & $11,40 \%$ \\
Rata-Rata & $12,07 \%$ & $14,83 \%$ & $13,01 \%$ \\
\hline
\end{tabular}

Secara deskriptif, nilai probabilitas Model dan Real dibandingkan pada Tabel 6. Nilai RMSE yang kecil menunjukkan perbedaan yang kecil antara nilai yang diperoleh dengan nilai pembanding. Terlihat bahwa nilai RMSE terkecil diperoleh pada Model A, yaitu sebesar 0,05; sedangkan nilai RMSE yang diperoleh pada Model C cukup besar, yaitu 0,306 .

Tabel 6 Analisis Deskriptif Nilai Probabilitas Model terhadap Nilai Real

\begin{tabular}{|c|c|c|c|c|}
\hline \multicolumn{5}{|c|}{ Grup A } \\
\hline & \multicolumn{2}{|c|}{ Mean } & \multirow{2}{*}{ Standar Deviasi Statistik } & \multirow{2}{*}{$\begin{array}{l}\text { Variansi } \\
\text { Statistik }\end{array}$} \\
\hline & Statistik & Std. Error & & \\
\hline Probabilitas Model & 0,575 & 0,06719 & 0,13437 & 0,01806 \\
\hline Probabilitas Real & 0,65215 & 0,06844 & 0,13688 & 0,01874 \\
\hline Selisih & & & 0,00250 & \\
\hline RMSE & & & 0,05000 & \\
\hline
\end{tabular}


Tabel 6 Analisis Deskriptif Nilai Probabilitas Model terhadap Nilai Real (Lanjutan)

\begin{tabular}{|c|c|c|c|c|}
\hline \multicolumn{5}{|c|}{ Grup B } \\
\hline & \multicolumn{2}{|c|}{ Mean } & \multirow{2}{*}{ Standar Deviasi Statistik } & \multirow{2}{*}{$\begin{array}{l}\text { Variansi } \\
\text { Statistik }\end{array}$} \\
\hline & Statistik & Std. Error & & \\
\hline Probabilitas Model & 0,6583 & 0,08858 & 0,17717 & 0,031 \\
\hline Probabilitas Real & 0,5753 & 0,08146 & 0,16292 & 0,027 \\
\hline Selisih & & & 0,01425 & \\
\hline RMSE & & & 0,11916 & \\
\hline \multicolumn{5}{|c|}{ Grup C } \\
\hline & \multicolumn{2}{|c|}{ Mean } & \multirow{2}{*}{ Standar Deviasi Statistik } & Variansi \\
\hline & Statistik & Std, Error & & Statistik \\
\hline Probabilitas Model & 0,75 & 0,14829 & 0,29659 & 0,088 \\
\hline Probabilitas Real & 0,7349 & 0,10159 & 0,20318 & 0,041 \\
\hline Selisih & & & 0,09341 & \\
\hline RMSE & & & 0,30561 & \\
\hline
\end{tabular}

\section{KESIMPULAN}

Berdasarkan data yang diperoleh dan analisis yang sudah dilakukan, kesimpulan yang dapat ditarik adalah bahwa faktor yang paling memengaruhi pilihan moda responden yang disurvei adalah tarif KRL. Peningkatan tarif KRL akan mengurangi probabilitas untuk memilih KRL atau sebaliknya penurunan tarif meningkatkan probabilitas penggunaan KRL. Pada penelitian ini dibentuk tiga fungsi utilitas berdasarkan kelompok respondennya, yang terdiri atas Fungsi Utilitas Responden dengan Perjalanan dari Ujung ke Ujung Trayek (Grup A), Fungsi Utilitas Responden Choice Riders dengan Perjalanan dari Ujung ke Ujung Trayek (Grup B), dan Fungsi Utilitas Responden Choice Riders, yang berpendapatan atau pengeluaran rata-rata lebih besar daripada Rp4.000.000,00 per bulan dengan Perjalanan dari Ujung ke Ujung Trayek (Grup C). Melalui pengujian model yang dilakukan terlihat bahwa model yang dibentuk oleh Grup A memiliki tingkat validasi yang paling baik pada split sample validation berdasarkan nilai rata-rata persentase eror dan RMSE. Namun model yang dibentuk oleh Grup C lebih baik pada pengujian kelayakan model (goodness of fit).

\section{DAFTAR PUSTAKA}

Armstrong, J. S. dan Collopy, F. 1992. Error Measures for Generalizing about Forecasting Methods: Empirical Comparisons. International Journal of Forecasting, 8: 69-80.

Blokhin, A. 2016. What is the Utility Function and How is It Calculated?. (Online), (http:// www.investopedia.com/ask/answers/072915/what-utility-function-and-how-it-calcu lated.asp, diakses 15 Maret 2016).

Bradley, MJ dan Associates. 2007. Comparison of Energy Use dan $\mathrm{CO}_{2}$ Emissions from Different Transportation Modes. Washington, DC: American Bus Association.

Hosmer, D. W. dan Lemeshow, S. 2000. Applied Logistic Regression. 2nd Edition. New York, NY: John Wiley dan Sons, Inc. 
Mathew, T.V. dan Rao, K.K. 2006. Introduction to Transportation Engineering. Mumbai.

Meyer, M. D. dan Miller, E.J. 1984. Urban Transportation Planning: A Decision-Oriented Approach. New York, NY: McGraw-Hill.

Nagelkerke, N. J. D. 1991. A Note on a General Definition of the Coefficient of Determination. Biometrika, 78 (3): 691-692.

Oppenheim, N. 1995. Urban Travel Demand Modeling: From Individual Choices to General Equibrilium. New York, NY: Wiley-Interscience.

Ortuzar, J.d. dan Willumsen, L.G. 2011. Modelling Transport. $4^{\text {th }}$ Edition. Hoboken, NJ: Wiley.

Rose, J.M. dan Bliemer, M.C. 2009. Sample Optimality in the Design of Stated Choice Experiments. The $12^{\text {th }}$ International Conference on Travel Behaviour Research. Jaipur.

Santoso, S. 2014. Statistik Non-Parametrik. Jakarta: PT Elex Media Komputindo.

The Coordinating Ministry of Economic Affairs; Japan International Cooperation Agency (JICA). 2012. JABODETABEK Urban Transportation Policy Integration (JUTPI) Project in the Republic of Indonesia. Jakarta.

Transportation Research Board. 2013. Transit Capacity and Quality of Service Manual. $3^{\text {rd }}$ Edition. Washington, DC: Parsons Brinckerhoff. 